\title{
CARACTERIZACÃO DA CHUVA HORÁRIA EM TRÊS LOCAIS DO ESTADO DE SÃO PAULO: UM SUBSÍDIO AO PLANEJAMENTO DE OPERAÇÕES AGRÍCOLAS DE CAMPO
}

\author{
J.E.M. PEZZOPANE; ;.C. SENTELHAS'; A.A. ORTOLAN ${ }^{2,3}$; A.V. DE C. MORAES ${ }^{2}$ \\ ${ }^{\prime}$ Centro Agropecuário da Universidade Federal do Espírito Santo, C.P. 16, CEP: 29.500-000, Alegre,ES \\ ${ }^{2}$ Instituto Agronômico de Campinas/IAC, C.P. 28, CEP:13001-970, Campinas,SP \\ ${ }^{3}$ Bolsista do .CNPq.
}

\begin{abstract}
RESUMO: Para caracterizar o comportamento das chuvas no decorrer do dia nos diferentes meses do ano, foram calculadas as médias dos totais e das frequiências das chuvas borárias para três locais: Campinas, Pindorama e Ubatuba, no periodo de 1957 a 1976 . Os resultados obtidos mostram que existe diferença significativa no total de chuva horária nos meses de: novembro a março em Campinas; outubro a abril em Pindorama, e outubro a junho em Ubatuba. A freqüência horária das chuvas apresentou resultados semelhantes aos do total de chuva para Campinas e Pindorama. Em Ubatuba, a freqüência horária das chuvas apresentou diferença significativa durante todos os meses do ano. Durante os meses que apresentam diferenças significativas, o periodo da manhã mostra ser o mais conveniente para a realização das atividades agrícolas, onde são reduzidas as probabilidades de chover. Durante os meses que não apresentaram diferença significativa, a probabilidade de ocorrência de chuvas é pequena. inferior a 10\%, em todos os horários do dia, sendo possivel programar operaçōes de campo durante todo o período. Descritores: chuva horária, frequiência horária, probabilidade
\end{abstract}

\section{HOURLY RAINFALL PATTERN FOR THREE SITES IN THE STATE OF SÃo PAULO, BRAZIL: A SUBSIDY TO AGRICULTURAL PRACTICES PLANNING.}

\begin{abstract}
This paper describes the rainfall pattern during the day along the different months of the year, calculated on an hourly basis for three sites: Campinas, Pindorama and Ubatuba, SP, Brazil, utilizing data series from 1957 to 1976. Results indicate that there is significative difference in the total of the hourly rainfall in the months of November to March in Campinas; October to April in Pindorama, and October to June in Ubatuba. Results of the hourly frequencies of rainfall are similar to those of total rainfall for Campinas and Pindorama. For Ubatuba, the hourly frequence of rainfall shows significant differences for all months of the year. During the months that show significant differences, the morning period is the most appropriate to realize agricultural practices, in which rainfall probability is reduced. During the months that do not show significant differences, the probability of rainfall occurrence is very reduced, less than $10 \%$, in average, in all hours of the day, being possible to program agricultural practices during the whole period.
\end{abstract}

Key words: hourly rainfall, hourly frequency, probability

\section{INTRODUÇÃO}

A aplicação de defensivos, colheita, preparo de solo, entre outras atividades agrícolas, representam custos elevados, envolvendo mão-deobra, emprego de maquinário e um planejamento prévio para a sua realização. O risco dessas atividades serem prejudicadas por chuvas na hora de sua realização é grande, desde que não se tenha de antemão um estudo da chuva ao longo do dia, caracterizando o seu comportamento.
Segundo ELLIOT \& HUNT (1975), chuvas maiores que $5 \mathrm{~mm}$ interferem na realização de operações de preparo do solo como a aração.

Vários autores realizaram estudos climatológicos do comportamento das chuvas e trovoadas ao longo do dia (WALLACE, 1975; SHWARTZ \& BOSART, 1979; EASTERLING \& ROBINSON, 1985; NECHET, 1992), possibilitando o entendimento da evolução desses fenômenos e o seu uso como subsídio às previsões de tempo e ao planejamento de atividades agrícolas. 
Estudando o período chuvoso na Venezuela, RIEHL \& LUECKEFEDT (1976) verificaram que fatores como orografia $e$ movimentos convectivos são determinantes no comportamento da chuva ao longo do dia.

WICHERLEY (1967), definiu a distribuição da chuva na Malásia para diferentes regiões, verificando uma grande variabilidade espacial, temporal e horária no seu comportamento. Esse estudo foi utilizado por HASSAN (1980) para determinação dos horários mais viáveis para a realização da sangria nos seringais de cada região.

CASTRO NETO \& SOUZA (1993) caracterizaram a frequência da chuva horária para Lavras, MG, visando o planejamento agrícola. Verificaram que no período chuvoso, de outubro a março, as maiores freqüências de chuva ocorreram entre as 17:00 e as 22:00 horas, e as menores, no período da manhã, horário mais propício à realização das atividades agrícolas. Resultados semelhantes foram obtidos por PEZZOPANE $e t$ al. (1993) no Estado de São Paulo.

$O$ presente trabalho tem como objetivo caracterizar o total e a freqüência horária das precipitações em três locais do Estado de São Paulo, para servir como subsídio ao planejamento e às tomadas de decisão das diversas atividades agrícolas.

\section{MATERIAL E MÉTODOS}

O trabalho se baseou em dados de chuva obtidos por pluviógrafos, de três Estações Experimentais do Instituto Agronômico: Campinas (lat.: 22 $2^{\circ} 3^{\prime} \mathrm{S}$; long.: $47^{\circ} 05^{\prime} \mathrm{W}$; alt.: $663 \mathrm{~m}$ ); Pindorama (lat.: $21^{\circ} 10^{\prime}$ 's; long.:48 $54^{\prime} \mathrm{W}$; alt.: 562 m) e Ubatuba (lat.: $23^{\circ} 27^{\prime}$ 's; long.: $45^{\circ} 03^{\prime} \mathrm{W}$; alt.: $8 \mathrm{~m}$ ), durante o período de janeiro de 1957 a dezembro de 1976 (20 anos).

Inicialmente o dia foi dividido em 24 intervalos de uma hora $(0$ à $1 h, 1$ às $2 h, \ldots, 23$ às $24 \mathrm{~h}$ ), obtendo-se o total médio mensal de precipitação para cada intervalo (p) como segue:

$$
P=p(h, m)=\frac{\Sigma P(h, m)}{n}
$$

onde: $\mathbf{P}$ representa $o$ total mensal de precipitação no intervalo de uma hora; $h$ representa o intervalo de uma hora; $m$ o mês em questão e n o número de anos de observação. Alem disso, foi determinada também a frequência média mensal de precipitação no intervalo de uma hora (f), como segue:

$$
f=f(h, m)=\frac{\sum N D(h, m)}{n}
$$

onde: ND é o número de dias no mês com chuva em um determinado intervalo de uma hora.

Assumindo válida a distribuição normal, os dados de $p$ e $f$ foram submetidos a análise de variância e teste $F$, para se verificar, para cada mês e para cada local, a existência de diferenças entre os 24 horários do dia.

Posteriormente, foram determinadas para cada intervalo de uma hora, a probbabilidade de chover acima de $0.1 \mathrm{~mm}$ e acima de $5.0 \mathrm{~mm}$, através do método da frequência relativa:

$$
P b(X h, m)=\frac{N D C 2 X(h, m)}{n \times d} \times 100
$$

onde: Pb é a probabilidade de ocorrência de chuvas maiores ou iguais a $X$, sendo $X$ igual a $0.1 \mathrm{~mm}$ ou $5.0 \mathrm{~mm}, \mathrm{em}$ um determinado intervalo de uma hora (h); $\mathbf{N D C}>=\mathbf{X}(\mathbf{h}, \mathrm{m})$ é o número de dias com chuva maior ou igual a $\mathbf{X}$ em um determinado intervalo de uma hora de um determinado mês (m); $\mathrm{n}$ é o número de anos e $\mathrm{d}$ o número de dius do mês em questão.

\section{RESULTADOS E DISCUSSÃO}

Nas TABELAS 1 e 2 são apresentados os resultados da análise de variância (teste $\mathrm{F}$ ) mensal do total médio $e$ da freqüência de precipitação para intervalos de uma hora ao longo do dia (p e f, respectivamente), nas três localidades estudadas. $O$ teste indicou que, durante os meses de verão, ou seja, no período chuvoso, existe uma diferença bastante significativa entre os valores de $p$ e de $\mathbf{f}$ nos diferentes horários do dia. $O$ teste mostrou ainda uma tendência das diferenças entre os valores de p (TABELA 1) persistirem mais em Pindorama, de outubro a abril, e em Ubatuba, de outubro a junho, em comparação a Campinas, que apresentou diferenças somente de novembro a março. Nos demais meses do ano, a análise não indicou haver diferenças significativas entre os valores de $p$ e f ao longo dos diferentes intervalos horários do dia.

A mesma tendência foi verificada para valores de $f$ (TABELA 2), com diferenças significativas em Pindorama, de outubro a abril, $\mathrm{em}$ Ubatuba durante todo $\mathrm{o}$ ano, enquanto $\mathrm{em}$ 
Campinas somente de dezembro a abril. Esses resultados se assemelham aos obtidos por CASTRO NETO \& SOUZA (1993) para Lavras, MG, que verificaram serem os meses do período chuvoso os que apresentam maiores diferenças na freqüência de chuvas ao longo do dia.

Baseados nos resultados obtidos nas TABELAS 1 e 2, foi escolhido um mês da estação chuvosa (janeiro) e um mês da estação seca (julho) de cada localidade para se caracterizar o comportamento da chuva ao longo do dia.

Nas figuras 1a e 1b são apresentados valores de $\mathbf{p}$ e $\mathbf{f}$ para os meses de janeiro e julho em Campinas. Pode-se verificar que no mês janeiro (figura 1a), há uma maior intensidade e freqüência das chuvas entre as 13:00 e as 24:00 horas, horários em que a probabilidade de chover acima de $0,1 \mathrm{~mm}$ varia de 12,0 a $20,0 \%$ (TABELA 3) e acima de $5,0 \mathrm{~mm}$ de 1,0 a 4,0\% (TABELA 4), com predominância de chuvas de origem convectiva. Nessa época as precipitações pluviais apresentam valores totais extremos às 18:00 horas, e maior freqüência às 20:00 horas. Já no mês de julho (figura 1b), quando predominam as chuvas frontais, não é observada tendência de concentração em um determinado horário, sendo a probabilidade de ocorrência inferior a $6,0 \%$ (TABELA 3).

Em Pindorama (figura 1c e 1d), o comportamento das chuvas horárias foi bastante semelhante ao de Campinas, apesar da menor intensidade e menor freqüência, principalmente no mês de julho. Em janeiro (figura 1c), as chuvas foram mais intensas entre as $14: 00$ e as 24:00 horas, com o pico às 18:00 horas, permanecendo com freqüência elevada até às 3:00 horas. Durante esse período a probabilidade de chover acima de $0,1 \mathrm{~mm}$ (TABELA 3) é de 12 a $15 \%$ e acima de $5,0 \mathrm{~mm}$ varia de 1,0 a $3,5 \%$ (TABELA 4 ).

TABELA 1 - Resultado da análise de variância do total médio mensal de precipitação entre os intervalos horários do dia, nos diferentes meses do ano em Campinas, Pindorama e Ubatuba, SP.

\begin{tabular}{|c|c|c|c|c|c|c|}
\hline \multirow[b]{3}{*}{ Meses } & \multicolumn{4}{|c|}{ Local } & & \\
\hline & \multicolumn{2}{|c|}{ Campinas } & \multicolumn{2}{|c|}{ Pindorama } & \multicolumn{2}{|c|}{ Ubatuba } \\
\hline & Diferença & Nível & Diferença & Nivel & Diferença & Nivel \\
\hline jan & $s$ & $1 \%$ & $s$ & $1 \%$ & $s$ & $1 \%$ \\
\hline fev & $s$ & $1 \%$ & $s$ & $1 \%$ & s & $1 \%$ \\
\hline $\operatorname{mar}$ & $s$ & $1 \%$ & $s$ & $1 \%$ & $s$ & $1 \%$ \\
\hline$a b r$ & $s$ & $1 \%$ & $\mathbf{s}$ & $1 \%$ & $\mathbf{S}$ & $1 \%$ \\
\hline mai & $N$ & - & $N$ & - & $s$ & $1 \%$ \\
\hline jun & $\mathrm{N}$ & - & $N$ & - & S & $1 \%$ \\
\hline jul & $N$ & - & $\mathrm{N}$ & - & $N$ & - \\
\hline ago & $\mathbf{N}$ & - & $N$ & - & $N$ & - \\
\hline set & $\mathbf{N}$ & - & $N$ & - & $\mathbf{N}$ & - \\
\hline out & $\mathbf{N}$ & - & $S$ & $1 \%$ & $\mathbf{s}$ & $1 \%$ \\
\hline nov & $s$ & $1 \%$ & $S$ & $1 \%$ & $\mathbf{s}$ & $1 \%$ \\
\hline dez & $\mathbf{S}$ & $1 \%$ & $\mathbf{S}$ & $1 \%$ & $\mathbf{s}$ & $1 \%$ \\
\hline
\end{tabular}

$S$ - significativo

$\mathrm{N}$ - não significativo

Sci. agric., Piracicaba, 52(1):70-77, jan./abr. 1995 

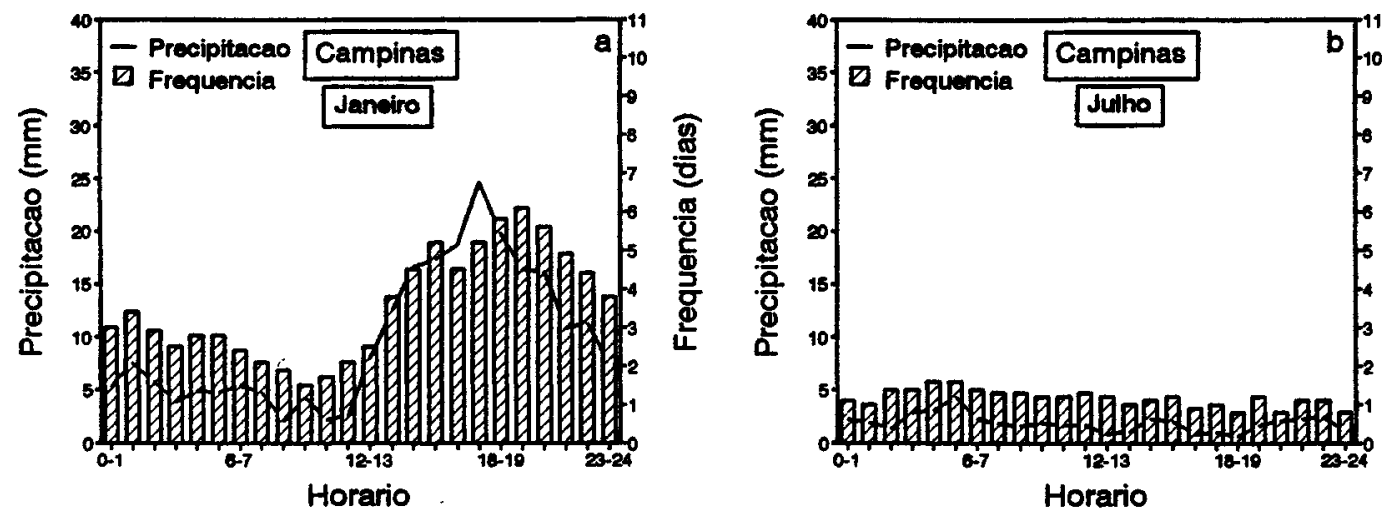

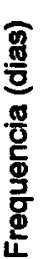
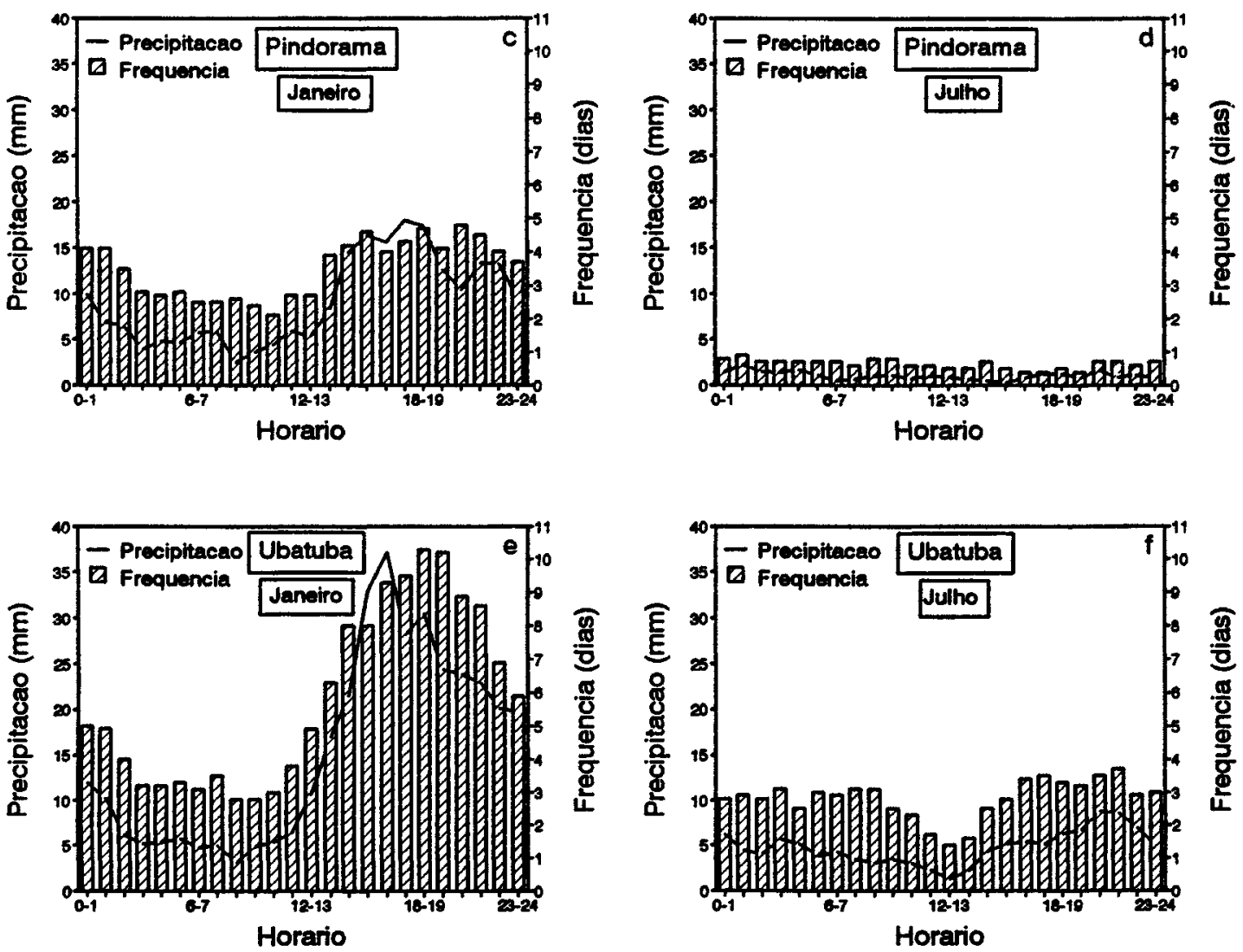

Figura 1. Comportamento do total e da freqüência da chuva horária durante os meses de janeiro e julho em Campinas, Pindorama e Ubatuba, SP. 


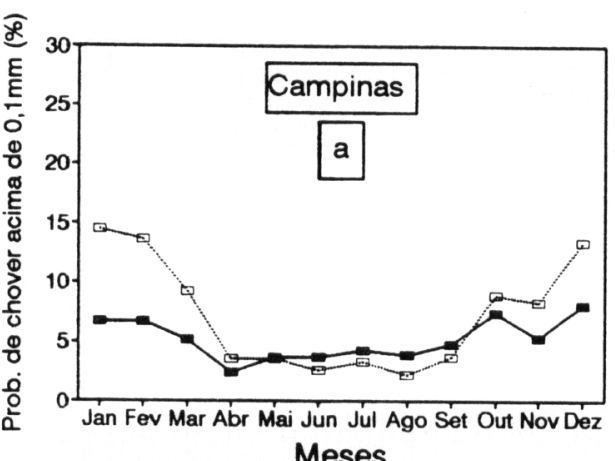

Meses

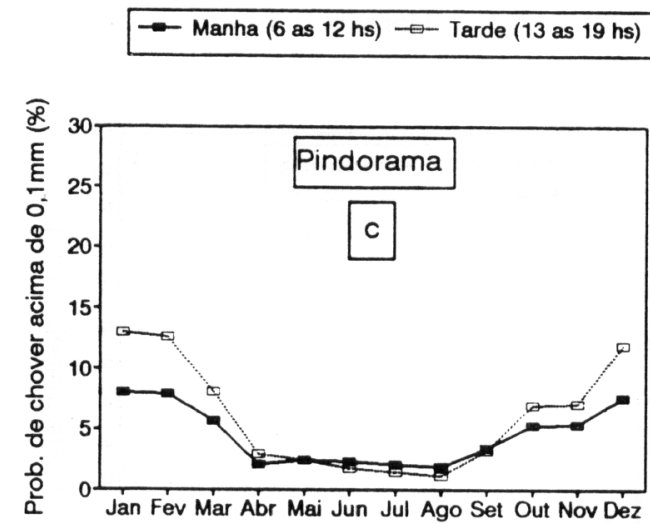

Meses

-- Manha $(6$ as $12 \mathrm{hs}) \rightarrow-$ Tarde $(13$ as $19 \mathrm{hs})$

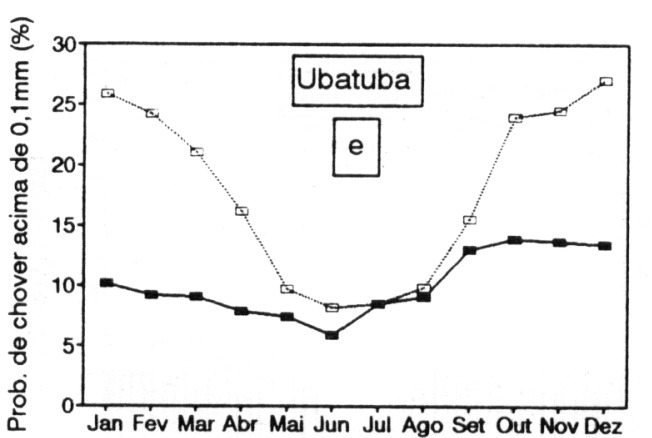

Meses

Manha (6 as $12 \mathrm{hs})-$ Tarde $(13$ as $19 \mathrm{hs})$

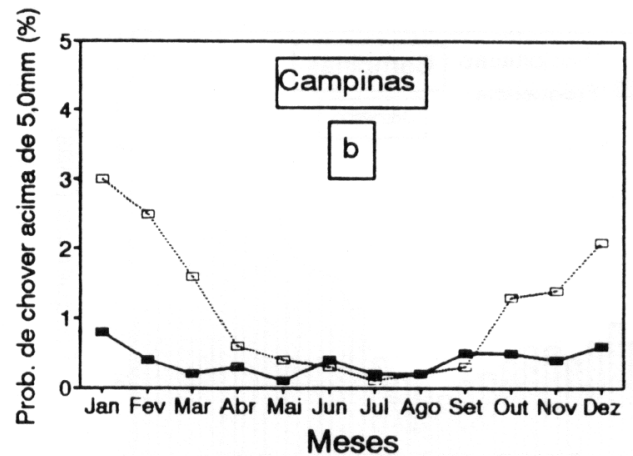

$\rightarrow-$ Manha (6 as $12 \mathrm{hs})-$ Tarde (13 as $19 \mathrm{hs})$

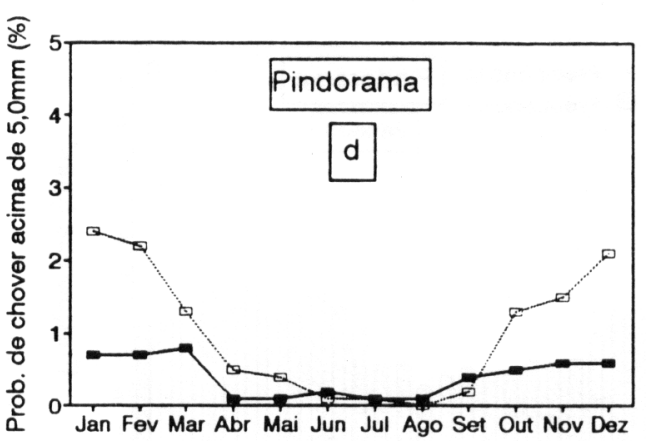

Meses

-- Manha (6 as $12 \mathrm{hs})-$ Tarde (13 as $19 \mathrm{hs})$

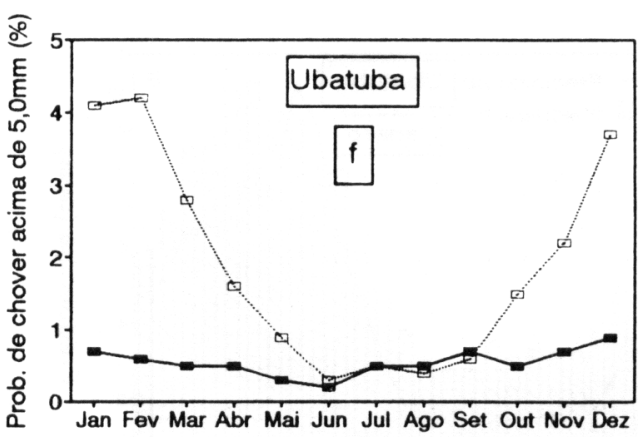

Meses

- Manha (6 as $12 \mathrm{hs})-$ Tarde (13 as $19 \mathrm{hs})$

Figura 2. Média das probabilidades de ocorrência de chuva em cada hora maior ou igual a $0,1 \mathrm{~mm}$ e 5,0 mm durante os períodos da manhã e da tarde em Campinas, Pindorama e Ubatuba, SP. 
TABELA 2. Resultado da análise de variância da freqüência média mensal de precipitação entre os intervalos horários do dia, nos diferentes meses do ano em Campinas, Pindorama e Ubatuba,SP.

\begin{tabular}{|c|c|c|c|c|c|c|}
\hline \multirow[b]{3}{*}{ Meses } & \multicolumn{4}{|c|}{ Local } & & \\
\hline & \multicolumn{2}{|c|}{ Campinas } & \multicolumn{2}{|c|}{ Pindorama } & \multicolumn{2}{|c|}{ Ubatuba } \\
\hline & Diferença & Nível & Diferença & Nível & Diferença & Nível \\
\hline jan & $\mathbf{S}$ & $1 \%$ & $S$ & $1 \%$ & $s$ & $1 \%$ \\
\hline fev & $S$ & $1 \%$ & $S$ & $1 \%$ & $s$ & $1 \%$ \\
\hline mar & $s$ & $1 \%$ & $S$ & $1 \%$ & $s$ & $1 \%$ \\
\hline$a b r$ & 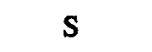 & $1 \%$ & $S$ & $1 \%$ & $\mathbf{S}$ & $1 \%$ \\
\hline mai & $\mathbf{N}$ & - & $N$ & - & $S$ & $1 \%$ \\
\hline jun & $N$ & - & $\mathbf{N}$ & - & $s$ & $1 \%$ \\
\hline jul & $N$ & - & $\mathbf{N}$ & - & $\mathbf{s}$ & $1 \%$ \\
\hline ago & $\mathbf{N}$ & - & $\mathrm{N}$ & - & $\mathbf{S}$ & $1 \%$ \\
\hline set & $N$ & - & $N$ & - & $\mathbf{S}$ & $1 \%$ \\
\hline out & $\mathrm{N}$ & - & $S$ & $1 \%$ & $S$ & $1 \%$ \\
\hline nov & $N$ & - & $s$ & $1 \%$ & $\mathbf{S}$ & $1 \%$ \\
\hline dez & $S$ & $1 \%$ & $s$ & $1 \%$ & $\mathbf{S}$ & $1 \%$ \\
\hline
\end{tabular}

$S$ - significativo

$\mathrm{N}$ - não significativo

Durante o período da manhã, entre as 6:00 e as 12:00 horas, as chuvas foram, em média, de 4 $\mathrm{mm}$, e com freqüência de 1 a 2 dias $/ \mathrm{mês}$, indicando baixa probabilidade de ocorrência, menor que $10,0 \%$, permitindo maior segurança para realização de operações agrícolas de campo. Em julho (figura 1d), a chuva e a freqüência foram bastante baixas, com probabilidades de ocorrência de chuvas inferiores a $3,0 \%$, não representando impecilhos às operações agrícolas de campo.

Em Ubatuba, no mês de janeiro (figura 1e), o comportamento, tanto do total médio mensal como da frequuência mensal da chuva, acompanhou a tendência dos demais locais, embora com valores mais elevados. Os horários de maior intensidade e freqüência das chuvas vão das 13:00 às 24:00 horas, com a frequêencia persistindo elevada até às 3:00 horas. Nesse intervalo, a probabilidade de chover varia de 15,0 a $33,0 \%$ (TABELA 3 ) e a de chover mais de $5,0 \mathrm{~mm}$ varia de 2,0 a $6,0 \%$ (TABELA 4). $O$ pico da chuva foi às 17:00 horas, com probabilidade de $6,29 \%$ de chover mais de $5 \mathrm{~mm}$ e o da freqüência às 19:00 horas, com probabilidade de $33 \%$ de chover. No mês de julho (figura 1f), os valores da chuva horária e da frequiência de sua ocorrência também apresentaram valores bem superiores aos demais locais. $O$ total de chuvas não apresentou diferença significativa estatisticamente ao longo do dia, apesar de uma leve tendência de chuvas mais elevadas no período da tarde. Já a frequêência de ocorrência, ao contrário dos demais locais, apresentou diferença significativa ao longo de todo o dia, sendo o período das $12: 00$ às 14:00 horas o de menor freqüência, com aproximadamente $5,0 \%$ de probabilidade de chover.

De um modo geral, para a realização das diversas atividades agrícolas que requerem 
ausência de chuva, o período da manhã mostra ser o mais conveniente, durante os meses de outubro a março em Campinas (figura $2 \mathrm{a}$ e 2b) e em Pindorama (figura $2 \mathrm{c}$ e $2 \mathrm{~d}$ ), período em que as probabilidades tanto de chover acima de $0,1 \mathrm{~mm}$ como acima de $5,0 \mathrm{~mm}$ são menores que no período da tarde. Nos demais meses do ano, essas probabilidades são praticamente iguais nos dois períodos, abaixo de $5 \%$ para $0,1 \mathrm{~mm}$ e de $1 \%$ para $5,0 \mathrm{~mm}$, podendo as operações agrícolas de campo serem planejadas para realização em qualquer horário do dia.

TABELA 3. Probabilidade de ocorrência (\%) de chuvas horárias maiores ou iguais a $0,1 \mathrm{~mm}$ para os meses de janeiro e julho em Campinas, Pindorama e Ubatuba. SP.

\begin{tabular}{|c|c|c|c|c|c|c|}
\hline \multirow[b]{2}{*}{ Horário } & \multicolumn{2}{|c|}{ Campinas } & \multicolumn{2}{|c|}{ Pindorama } & \multicolumn{2}{|c|}{ Ubatuba } \\
\hline & Jan. & Jul. & Jan. & Jul. & Jan. & Jul. \\
\hline 0 à $1 \mathrm{~h}$ & 9,7 & 3,5 & 13,1 & 2,4 & 16,0 & 8,9 \\
\hline 1 às $2 \mathrm{~h}$ & 11,0 & 3,2 & 13,1 & 2,7 & 15,8 & 9,4 \\
\hline 2 às $3 \mathrm{~h}$ & 9,4 & 4,5 & 11,3 & 2,1 & 12,9 & 9,0 \\
\hline 3 às $4 \mathrm{~h}$ & 8,1 & 4,5 & 8,9 & 2,1 & 10,3 & 10,0 \\
\hline 4 às 5 h & 9,0 & 5,2 & 8,7 & 2,1 & 10,2 & 7,9 \\
\hline 5 às $6 \mathrm{~h}$ & 9,0 & 5,2 & 9,0 & 2,1 & 10,5 & 9,7 \\
\hline 6 às $7 \mathrm{~h}$ & 7,7 & 4,5 & 8,1 & 2,1 & 9,8 & 9,4 \\
\hline 7 às $8 \mathrm{~h}$ & 6,8 & 4,2 & 7,9 & 1,8 & 11,3 & 10,0 \\
\hline 8 às $9 h$ & 6,1 & 4,2 & 8,4 & 2,4 & 8,9 & 9,8 \\
\hline 9 às $10 \mathrm{~h}$ & 4,8 & 3,9 & 7,6 & 2,4 & 8,9 & 7,9 \\
\hline 10 às $11 \mathrm{~h}$ & 5,5 & 3,9 & 6,6 & 1,9 & 9,5 & 7,3 \\
\hline 11 às $12 \mathrm{~h}$ & 6,8 & 4,2 & 8,5 & 1,9 & 12,3 & 5,3 \\
\hline 12 às $13 \mathrm{~h}$ & 8,1 & 3,9 & 8,5 & 1,5 & 15,6 & 4,5 \\
\hline 13 às $14 \mathrm{~h}$ & 12,3 & 3,2 & 12,6 & 1,5 & 20,2 & 5,2 \\
\hline 14 às $15 \mathrm{~h}$ & 14,5 & 3,5 & 13,4 & 2,1 & 25,8 & 8,1 \\
\hline 15 às $16 \mathrm{~h}$ & 16,8 & 3,9 & 14,7 & 1,6 & 25,8 & 8,9 \\
\hline 16 às $17 \mathrm{~h}$ & 14,5 & 2,9 & 12,9 & 1,3 & 30,0 & 10,8 \\
\hline 17 às $18 \mathrm{~h}$ & 16,8 & 3,2 & 13,9 & 1,3 & 30,6 & 11,3 \\
\hline 18 às $19 \mathrm{~h}$ & 18,7 & 2,6 & 15,2 & 1,5 & 33,2 & 10,5 \\
\hline 19 às $20 \mathrm{~h}$ & 19,7 & 3,9 & 13,1 & 1,3 & 32,9 & 10,2 \\
\hline 20 às $21 \mathrm{~h}$ & 18,1 & $2, C$ & 15,3 & 2,1 & 28,5 & 11,3 \\
\hline 21 às $22 \mathrm{~h}$ & 15,8 & 3,5 & 14,4 & 2,1 & 27,7 & 11,9 \\
\hline 22 às $23 \mathrm{~h}$ & 14,2 & 3,5 & 12,9 & 1,8 & 22,3 & 9,4 \\
\hline 23 às $24 \mathrm{~h}$ & 12,3 & 2,6 & 11,9 & 2,1 & 18,9 & 9,5 \\
\hline
\end{tabular}

Em Ubatuba (figura 2e e 2f) somente nos meses de junho a setembro não existe diferenças nas probabilidades de chuva nos períodos da manhã e da tarde. Nos demais meses, o período da manhã tem se mostrado sempre mais viável à realização de operações agrícolas de campo, ou seja, com menores probabilidades de ocorrência de chuvas acima de $5,0 \mathrm{~mm}$.

TABELA 4. Probabilidade de ocorrência (\%) de chuvas horárias maiores ou iguais a $5,0 \mathrm{~mm}$ para os meses de janeiro e julho em Campinas, Pindorama e Ubatuba, SP.

\begin{tabular}{|c|c|c|c|c|c|c|}
\hline \multirow[b]{2}{*}{ Horário } & \multicolumn{2}{|c|}{ Campinas } & \multicolumn{2}{|c|}{ Pindorama } & \multicolumn{2}{|c|}{ Ubatuba } \\
\hline & Jan. & Jul. & Jan. & Jul. & Jan. & Jul. \\
\hline 0 à $1 \mathrm{~h}$ & 0,72 & 0,57 & 1,13 & 0,16 & 1,45 & 0,81 \\
\hline 1 às $2 \mathrm{~h}$ & 1,79 & 0,38 & 1,45 & 0,16 & 1,94 & 0,65 \\
\hline 2 às $3 \mathrm{~h}$ & 1,25 & 0,19 & 0,97 & 0,16 & 0,81 & 0,32 \\
\hline 3 às $4 h$ & 0,18 & 0,38 & 0,48 & 0,00 & 0,65 & 1,13 \\
\hline 4 às 5 h & 1,08 & 0,19 & 1,13 & 0,32 & 0,32 & 0,97 \\
\hline 5 às $6 \mathrm{~h}$ & 1,08 & 0,19 & 0,81 & 0,16 & 0,48 & 0,81 \\
\hline 6 às $7 \mathrm{~h}$ & 1,43 & 0,00 & 0,48 & 0,00 & 0,48 & 0,65 \\
\hline 7 às 8 h & 0,90 & 0,00 & 13 & 0,16 & 0,65 & 0,48 \\
\hline 8 às $9 h$ & 0,54 & 0,00 & 0,16 & 0,32 & 0,65 & 0,32 \\
\hline às $10 \mathrm{~h}$ & 1,08 & 0,38 & 0,16 & 0,00 & 0,97 & 0,48 \\
\hline 10 às $11 \mathrm{~h}$ & 0,18 & 0,38 & 0,81 & 0,16 & 1,13 & 0,16 \\
\hline s $12 \mathrm{~h}$ & 0,54 & & & 0 , & 5 & 0,32 \\
\hline 12 às $13 \mathrm{~h}$ & 1,43 & 0,19 & 1,13 & 0,16 & 2,10 & 0,00 \\
\hline 13 às $14 \mathrm{~h}$ & 2,87 & 0,00 & 1,77 & 0,00 & 2,42 & 0,16 \\
\hline 14 às $15 \mathrm{~h}$ & 3,05 & 0,00 & 2,26 & 0,00 & 4,52 & 0,65 \\
\hline 15 às $16 \mathrm{~h}$ & 2,87 & 0 & 9 & 20 & 7 & 0,65 \\
\hline 16 às $17 \mathrm{~h}$ & 2,87 & 0,19 & 3,23 & 0,16 & 6,29 & 0,48 \\
\hline 17 às $18 \mathrm{~h}$ & 3,94 & 0,00 & 2,74 & 0,32 & 5,48 & 0,81 \\
\hline 18 às $19 \mathrm{~h}$ & 3,76 & 0,00 & 2,58 & 0,32 & 3,87 & 0,81 \\
\hline 19 às $20 \mathrm{~h}$ & 3,41 & 0,19 & 2,26 & 0,16 & 4,52 & 0,81 \\
\hline 20 às $21 \mathrm{~h}$ & 3,05 & 0,38 & 1,77 & 0,32 & 4,35 & 0,65 \\
\hline 21 às $22 \mathrm{~h}$ & 1,61 & 0,19 & 2,26 & 0,16 & 3,87 & 1,29 \\
\hline 22 às $23 \mathrm{~h}$ & 1,79 & 0,57 & 1,77 & 0,32 & 3,06 & 0,65 \\
\hline 23 às $24 \mathrm{~h}$ & 1,25 & 0,19 & 1,77 & 0,00 & 2,90 & 0,65 \\
\hline
\end{tabular}

\section{CONCLUSÕES}

a) durante os meses de outubro a março em Campinas e em Pindorama e de outubro a maio em Ubatuba, os melhores horários, sob luz solar para realização das operações agrícolas de campo, ocorrem das 6:00 às 12:00 horas, quando as probabilidades de ocorrência de chuva são reduzidas;

b) o período menos favorável, durante os meses de outubro a março em Campinas e em Pindorama e 
de outubro a maio em Ubatuba, é a partir das 14:00 horas, quando ocorrem as chuvas convectivas de verão e as probabilidades de ocorrência de chuva tornam-se elevadas;

c) nos meses de abril a setembro em Campinas e em Pindorama e de junho a setembro em Ubatuba, de modo geral, não há diferenças significativas, nas probabilidades de ocorrencia de chuva nos diferentes horários do dia, sendo possível planejar operaçôes agrícolas de campo durante todo o período diumo.

\section{RÉFERENCIAS BIBLIOGRÁFICAS}

CASTRO NETO, P.; SOUZA, J.L.M. Frequência horf́ria de chuvas em Lavras, Estado de Minas Gerais. In: CONGRESSO BRASILEIRO DE AGROMETEOROLOGIA, 8., Porto Alegre, 1993. Resumos... Porto Alegre: Sociedade Brasileira de Agrometeorologia, Universidade Federal do Rio Grande do Sul, 1993. p.40.

EASTERLING, D.R.; ROBINSON, P.J. The diurnal variation of Thunderstorm activity in the United States. Journal of Crimate and Applied Meteorology, Boston, v.24, n.10, p.1048-1058, 1985.

ELLIOT, R.L.; HUNT, D.R. A simulation model for predicting available days for tillage. St. Joseph: ASAE, 1975. 13p. (ASAE. Paper, 75-1501).

HASSAN, A. Nursery techniques for rubber plant propagation. Kuala Lumpur: Rubber Research Institute of Malaysia, 1980.89p.
NECHET, D. Variabilidade diuma de precipitação e de trovoadas em Manaus, AM. In: CONGRESSO BRASILERO DE METEOROLOGIA, 7., Sāo Paulo, 1992. Anais... São Paulo: Sociedade Brasileira de Meteorologia, Universidade de São Paulo, 1992, p.243-247.

PEZZOPANE, J.E.M.; ORTOLANI, A.A.; SENTELHAS, P.C.; MELLO, M.H.A. Caracterizaçăo da chuva horária no Estado de São Paulo. In: CONGRESSO BRASILEIRO DE AGROMETEOROLOGIA, 8., Porto Alegre, 1993. Resumos... Porto Alegre: Sociedade Brasileira de Agrometeorologia, Universidade Federal do Rio Grande do Sul, 1993. p.41.

RIEHL, H.; LUECKEFEDT, W. Precipitation and thermodinamic structure of rain events in Venezuela. Monthly Weather Review, Boston, v.104, n.9, p.1162-1166, 1976.

SHWARTZ, B.E.; BOSART, L.F. The diurnal variability of Florida rainfall. Monthly Weather Review, Boston, v.107, p.1535-1545, 1979.

WALLACE, J.M. Diurnal variations in precipitation and thunderstorm frequency over the conterminous United States. Monthly Weather Review, Boston, v.103, p.406-419, 1975.

WYCHERLEY, P.R. Rainfall in Malaysia. Panting Mannal Rubber Research Institute, Kuala Lumpur, n.12, 1967.

Entregue para publicação em 30.05.94

Aceito para publicação em 25.10.94 